\title{
Heterozygote of TAP1 Codon637 decreases susceptibility to HPV infection but increases susceptibility to esophageal cancer among the Kazakh populations
}

Ningjing Zou ${ }^{1+}$, Lan Yang ${ }^{1 \dagger}$, Ling Chen ${ }^{1+}$, Tingting $\mathrm{Li}^{1}$, Tingting Jin ${ }^{1}$, Hao Peng ${ }^{1}$, Shumao Zhang ${ }^{1}$, Dandan Wang ${ }^{1}$, Ranran Li ${ }^{1}$, Chunxia Liu', Jinfang Jiang ${ }^{1}$, Lianghai Wang ${ }^{1}$, Weihua Liang ${ }^{1}$, Jianming Hu' ${ }^{1}$, Shugang Li', Chuanyue $\mathrm{Wu}^{1,3}$, Xiaobin Cui ${ }^{1,2^{*}}$, Yunzhao Chen ${ }^{1,2^{*}}$ and Feng $\mathrm{Li}^{1,2^{*}}$

\begin{abstract}
Background: The role of human papillomavirus (HPV) may be involved in the development of esophageal cancer (EC) and the polymorphic immune response gene transporter associated with antigen processing (TAP) may be involved in HPV persistence and subsequent cancer carcinogenesis. The current study aims to provide association evidence for HPV with EC, to investigate TAP1 polymorphisms in EC and assess its association with HPV statuses and EC in Kazakhs.

Methods: The HPV genotypes in 361 patients with EC and 66 controls selected from Kazakh population were evaluated using PCR. Polymerase chain reaction-restriction fragment length polymorphism (PCR-RFLP) was performed to detect two SNPs of TAP1 in 150 cases comprised of $75 \mathrm{HPV}^{+}$and $75 \mathrm{HPV}$ patients and 283 pure ethnic population of Kazakh and evaluate their associations with susceptibility to EC. A case-to-case comparison based on the genotyping results was conducted to address the function of TAP1 variants in the involvement of HPV.
\end{abstract}

Results: The presence of four HPV genotypes in EC tissues - including HPV 16, 18, 31, 45 - was significantly higher at $64.6 \%$ than those in controls at $18.2 \%(P<0.001)$. Such presence was strongly associated with increased risk of EC (OR 8.196; $95 \% \mathrm{Cl}$ 4.280-15.964). The infection of HPV16, and multi-infection of 16 and 18 significantly increase the risk for developing EC (OR 4.616, $95 \%$ Cl 2.099-10.151; and OR 6.029, $95 \%$ Cl 1.395-26.057 respectively). Heterozygote of TAP1 D637G had a significantly higher risk for developing EC (OR 1.626; $95 \% \mathrm{Cl} 1.080-2.449)$. The odds ratio for HPV infection was significantly lower among carriers of TAP1 D637G polymorphism (OR 0.281; 95 \% Cl 0.144-0.551).

Conclusions: HPV infection exhibits a strong positive association with the risk of EC in Kazakhs. Heterozygote of TAP1 D637G decreases susceptibility to HPV infection in patients with EC but increases susceptibility to EC among the Kazakh populations.

Keywords: Esophageal squamous cell carcinoma, Human papillomavirus, Transporter associated with antigen processing, Single nucleotide polymorphism

\footnotetext{
*Correspondence: 342029924@qq.com; cyz0515@sina.com; lifeng7855@126.com

†Equal contributors

'Department of Pathology and Key Laboratory for Xinjiang Endemic and Ethnic Diseases, Shihezi University School of Medicine, North 4th Road,

Shihezi, Xinjiang 832002, China

Full list of author information is available at the end of the article
} 


\section{Introduction}

Esophageal cancer, one of the most aggressive malignancies originating in the gastrointestinal tract, as well as, the sixth most frequent cause of cancer-related death worldwide, with wide geographic, ethnic or social cultural variation, results in more than 400,000 deaths annually $[1,2]$. The two main histological types of esophageal cancer: esophageal squamous cell carcinoma (ESCC) and esophageal adenocarcinoma (EAC), of which the former is predominant type accounting for more than $80 \%$ in China [3]. Comparing with other areas and ethnic groups of China, the Kazakh population, a nomadic tribe and mainly residing in the northwest of Xinjiang Province, shows high incidence and mortality of ESCC, with the highest age-adjusted mortality of 90.7/100,000 among all of the ethnic populations in Xinjiang [4]. Epidemiological studies have shown that heavy smoking and alcohol consumption, the main environmental risk factors for ESCC in Europe and North America [5-7], however seem to be minor risk factors for ESCC in the high-incidence areas in China $[8,9]$. Therefore, other risk factors should be considered to explain the high incidence of ESCC in these areas.

Human papillomavirus (HPV), a nonenveloped doublestranded DNA virus with more than 120 kinds of subtypes have been separated, including more than 80 kinds of DNA sequencing, is a crucial tumor-related virus. HPV DNA has been detected in more than $90 \%$ of cervical cancer specimens [10]. Notably, several studies indicated that HPV infection was found in extra genital cancers, such as $30 \%$ of the human head and neck cancer and oral and oropharyngeal squamous cell carcinoma [11, 12], however, the etiological implication of HPV in these malignancies remains controversial [13]. In 1982, the association between HPV and EC was first reported that HPV infection caused pathological lesions in EC specimens [14]. Subsequent studies conducted in different geographic areas and ethnic groups, such as Han ethnic group in eastern China (Linxian and Anyang in Henan Province, Cixian in Hebei, Yangcheng in Shanxi and the northern Jiangsu province) and Kazakh minority residing in the northwest part of China, have shown large variations in the prevalence of HPV among EC patients, ranging from 0 to $100 \%$ [15-20], which brought about opposite conclusions in the influence of HPV on the development of EC. The discrepancies may be generally attributed to the small size of the samples, differences in immunological and molecular methods, as well as inter-laboratory variability in sample collection and handling [21,22]. In previous studies, HPV infection rate in EC in Kazakh patients varied from 18.6 to $41.1 \%$ [19, 23, 24]. It comes up that the role of HPV infection in esophageal epithelium carcinogenesis is puzzling.
However, HPV alone is not sufficient to induce malignant transformation. The long-held theory of immune surveillance indicates that the alert immune system permanently prevent the growth of cancer by recognizing and eliminating the vast majority of incipient cancer cells and thus nascent tumors [25]. The major histocompatibility complex $(\mathrm{MHC})$ plays a major role in the immune response against viral infections and transformed cells by presenting peptide antigens to cytotoxic $\mathrm{T}$ lymphocytes [26-28]. The transporter associated with antigen processing (TAP), whose genes are encoded in the MHC class II region of chromosome 6 , is a critical component of the major histocompatibility complex (MHC) class I antigen presentation $[29,30]$. Transporter associated with antigen processing is composed of two integral membrane proteins, TAP1 and TAP2, TAP1 functions by providing a supply of candidate peptides to the MHC-I molecules within the peptide loading complex and by transporting antigen peptides from the cytoplasm into the endoplasmic reticulum, [31, 32]. Regarding EC, the loss of expression of MHC class I and TAP1 has been reported to render some tumor cells to escape the immune surveillance and contribute to the clinical course of EC [33].

Some single nucleotide polymorphisms (SNPs) of TAP gene appear to influence the antigen peptide selection and transport process, and have been confirmed to be susceptible to various human diseases including immune diseases [34-36], infectious diseases [37-40] and tumors [41-43]. However, there has been only one study on the association of TAP polymorphisms and EC [44]. In this study, five gene polymorphisms including two at TAP1 and three at TAP2 were genotyped using polymerase chain reaction-restriction fragment length polymorphism (PCR-RFLP) method in 265 cases of ESCC and 357 controls. The results show no significant difference between the polymorphisms at TAP1 I333V and D637G and EC in Anyang, Henan. Given that TAP1 plays an important role in immune response and the polymorphisms of this gene may result in the conformational and functional change, and thus may affect individual's susceptibility to HPV infection and subsequently the HPV-associated cancer development. What's more, the distribution of Codon 333 and 637 polymorphisms of TAP1 and its relationship with HPV infection and EC remains unknown among the Kazakh population. Therefore the two potentially functional SNPs of this immune response gene to HPV must be investigated to define individuals with higher risk of developing malignant disease.

Therefore, the present study is employed to identify whether HPV infection is linked to the etiology of EC using PCR in 316 EC specimens and 66 biopsy samples of normal esophageal squamous epithelium from the Yili, an area with high incidence of EC. Additionally, 150 paraffin-embeded tumor specimens and 283 matched 
cancer-free controls were used to investigate the association between TAP1 polymorphisms and risk of EC in this ethnic and to accumulate evidence regarding the potential role of TAP polymorphisms in the disease. Subsequently, a case-to-case comparison based on the genotyping results was conducted to address the possible function of the TAP1 variants in the involvement of HPV in Kazakh patients with EC.

\section{Materials and methods}

\section{Specimens used for detecting HPV infection}

A total of 316 EC specimens of Kazakh in formalin-fixed paraffin-embedded archival tissues were collected from the People's Hospital of Xinjiang Uyghur Autonomous Region, the First University Hospital, Shihezi University School of Medicine and several hospitals in the Yili Kazakh Autonomous Prefecture. The 316 cases were diagnosed between January 1990 and March 2014, and they were all diagnosed as ESCC. The pathological grade of tumors was classified at the time of diagnosis. Patients had received neither chemotherapy nor radiotherapy before endoscopies and surgery. All samples were surgically resected and fixed in $10 \%$ buffered-formalin, routinely processed, and paraffin-embedded. The specimens of Kazakh patients were all obtained from the high-incidence areas in Xinjiang. From the patients' medical records, we gathered data on clinical pathological variables such as tumor site, invasion depth, and distant metastasis. All cases of pathological diagnosis for the tumor-node- metastasis (TNM) stages were evaluated according to Cancer Stage Manual 7th Edition 2009 issued in 2009 by the American Joint Committee on Cancer (AJCC/UICC). Informed consent of each patient was obtained, and study protocol was approved by the Institutional Review Board at Shihezi University School of Medicine. Biopsy samples of normal esophageal squamous epithelium were available from 66 control patients matched for ethnicity, who were from Kazakh-gathering place in Xinyuan, Yili and participated in the project of Early Diagnosis and Treatment of EC in Xinjiang Province. Each control had undergone upper gastrointestinal endoscopy and the esophageal tissue samples were confirmed as histologically normal. At the same time, the control subjects' corresponding pathological and clinical data were gained.

The patients in this study were comprised of 187 men and 129 women with an average age of $52.89 \pm$ 8.923 years (ranging from 23 to 79 years). In addition, a total of 36 men and 30 women control subjects were matched with an average age of $50.67 \pm 11.542$ years (ranging from 19 to 64 years). The difference between cases and controls is of no significance in gender $(P=$ $0.488)$ and age $(\mathrm{t}=1.741, P=0.083)$ distribution. The cases included 106 (33.5\%) well-differentiated patients (group G1), $162(51.3 \%)$ moderately differentiated patients (G2), and 48 (15.2\%) poorly differentiated patients (G3). When evaluated according to Cancer Stage Manual 7th Edition 2009, the 316 ESCC cases, 48 (15.2\%) were classified as stage I, $183(58.0 \%)$ as stage II, 75 $(23.7 \%)$ as stage III, and $10(3.1 \%)$ as stage IV. Of the 316 ESCC cases, 30 (9.5\%) were classified as T1, 158 $(50.0 \%)$ as T2, $123(38.9 \%)$ as T3, and $5(1.6 \%)$ as T4.

\section{Specimens used for testing TAP1 gene polymorphisms}

The 316 Kazakh patients with EC mentioned above, which had been tested for HPV infection, was then divided into two groups (204 cases infected with HPV and 112 cases that weren't), from both of which we selected 75 cases respectively and at random, so a total of 150 paraffin-embedded tumor specimens were used for genotyping TAP1 gene. The 283 controls were selected randomly from a pool of cancer-free subjects recruited from Kazakh ethnic population in Xinyuan, Yili, who had visited the hospital for a conventional cancer screening program. Blood samples were collected and DNA was extracted for the genotyping of TAP1 gene. Informed consent was obtained from all participants in this study.

The patients in this study were comprised of 94 men and 56 women with an average age of $52.29 \pm 9.571$ years (ranging from 23 to 75 years). In addition, a total of 154 men and 129 women control subjects were matched with an average age of $50.25 \pm 11.991$ years (ranging from 21 to 72 years). The difference in gender distribution between cases and controls is of no significance $(P=0.098)$, however, age distribution differs significantly between cases and controls $(t=1.801, P=0.072)$.

\section{Detection of HPV DNA}

DNA was extracted from the paraffin sections and biopsy samples using standard proteinase $\mathrm{K}$ digestion and a tissue DNA extraction kit (Qiagen, Hilden, Germany) according to the manufacturer's instructions. As an internal control, all purified genomic DNA samples were successfully tested by polymerase chain reaction (PCR) with a human $\beta$-actin primer set (forward: 5'-CAGACACCATG GTGCACCTGAC-3' and reverse: 5'-CCAATAGGCAGA GAGAGTCAGTG-3'), indicating that the quality and quantity of DNA were suitable for detecting the presence of HPV. The HPV infection was first determined by PCR using non-degenerate primer set, GP 5+/6+, Forward primer: TTGGATCCTTTGTACTGTGGTAGATACTAC and Reverse primer: TTGGATCCGAAAAATAAACTGTAAA TCATATTC, which produce a $150 \mathrm{bp}$ ragment of L1 gene in a wide range of HPV types. For HPV 16 DNA detection, E7 was amplified with forward primer GATGAAATAG ATGGTCC AGC and reverse primer GCTTTGTACGCA CAACCGAGC. For each PCR reaction, $5 \mu \mathrm{L}$ extracted 
concentrated DNA was used in a final reaction volume of $25 \mu \mathrm{L}$. The reaction was initially carried out at $95{ }^{\circ} \mathrm{C}$ for $10 \mathrm{~min}$, followed by 40 cycles of denaturation at $94{ }^{\circ} \mathrm{C}$ for $30 \mathrm{~s}$, annealing at $42{ }^{\circ} \mathrm{C}$ for $90 \mathrm{~s}$, and extension at $72{ }^{\circ} \mathrm{C}$ for $30 \mathrm{~s}$, with a final extension at $72{ }^{\circ} \mathrm{C}$ for $5 \mathrm{~min}$. The amplicons were then denatured and subjected to hybridization. Assays of the samples were run in triplicate, with positive and negative controls (CaSki cell DNA generously provided by Professor Yang Ke, Beijing Institute for Cancer Prevention Laboratory and distilled water) (Fig. 1). $\beta$ - actin was used as a DNA control. To confirm the accuracy of the HPV genotyping by PCR, $10 \%$ DNA sequence of the positive products was then identified by NCBI Blast (Fig. 2). A $100 \%$ match was identified between the results of DNA sequence displayed in the Genbank and HPV genotype detected.

\section{Genotyping TAP1 I333V and D637G polymorphisms}

DNA was extracted from the paraffin sections and blood samples using standard proteinase $\mathrm{K}$ digestion and a tissue DNA extraction kit (Qiagen, Hilden, Germany) according to the manufacturer's instructions. The two previously documented polymorphisms in TAP1 coding regions are previously documented. The primers used in PCR to detect for Codon 333 were as follows: forward primer GCAGGTAACATC ATGTCTCG and Reverse primer: GACAGATTGTGGGGAGAAGC, and for Codon 637 were as follows: forward primer CAGTAGTCTTGCCTT TATCC and Reverse primer: ATGACTGCCTCACCTGT AAC. The PCR was carried out in $25 \mathrm{ml}$ reaction mixture containing genomic $1 \mathrm{ml}$ DNA, $2.5 \mathrm{ml} 10 \times$ PCR buffer
(100 mM Tris, $\mathrm{pH} 7.8,100 \mathrm{mM} \mathrm{NaCl}, 10 \mathrm{mM}$ EDTA and $0.5 \%$ SDS), $1.8 \mathrm{ml}$ of $25 \mathrm{mM} \mathrm{MgCl}_{2}, 0.5 \mathrm{ml}$ of $10 \mathrm{mM}$ $\mathrm{dNTP}$ each, $10 \mathrm{pmol}$ primer and $1.5 \mathrm{U}$ of Taq polymerase (Promega, Madison, WI, USA). The reaction was initially carried out at $94{ }^{\circ} \mathrm{C}$ for $2 \mathrm{~min}$, followed by 35 rounds of thermal cycling were in the conditions: denaturation at $94{ }^{\circ} \mathrm{C}$ for $40 \mathrm{~s}$, annealing at $57.5^{\circ} \mathrm{C}$ for $40 \mathrm{~s}$, extension at $72{ }^{\circ} \mathrm{C}$ for $40 \mathrm{~s}$ and the final extension was carried out at $72{ }^{\circ} \mathrm{C}$ for $10 \mathrm{~min}$. The terminator ready sequencin was performed in a total volume of $20 \mathrm{ml}$ containing $8 \mathrm{ml}$ of PCR product, $2.5 \mathrm{ml} 10 \times$ PCR buffer, the enzymes used were $7 \mathrm{U}$ of Bcl1 and Acc1 for genotyping Codon 333 and Codon 637 respectively. Cycling conditions were as follows: initial denaturing $96{ }^{\circ} \mathrm{C}$ for 2 min, followed by 30 cycles at $94{ }^{\circ} \mathrm{C}$ for $10 \mathrm{~s}, 50{ }^{\circ} \mathrm{C}$ for $5 \mathrm{~s}$ and $60{ }^{\circ} \mathrm{C}$ for $4 \mathrm{~min}$. Restriction enzyme digestion with Bcl1 and Acc1 (Promega, Madison, WI, USA) of the PCR product was carried out overnight and analyzed on a $3 \%$ agarose gel. DNA products were visualized by ethidium bromide staining (Fig. 3). The -333A and $-637 \mathrm{~A}$ showed two fragments (homozygous for the allele $-333 \mathrm{~A}$ and $-637 \mathrm{~A})$, while its homologue $-333 \mathrm{G}$ and $-637 \mathrm{G}$ was undigested and resulted in a single band (homozygous for allele $-333 \mathrm{G}$ and $-637 \mathrm{G}$ ). The presence of all three fragments defined heterozygotic individuals. To confirm the accuracy of TAP1 I333V and D637G genotyping by PCR, $10 \%$ DNA sequence of the PCR products was then identified by NCBI Blast (Fig. 4). A $100 \%$ match was identified between the results of DNA sequence displayed in the Genbank and HPV genotype detected.

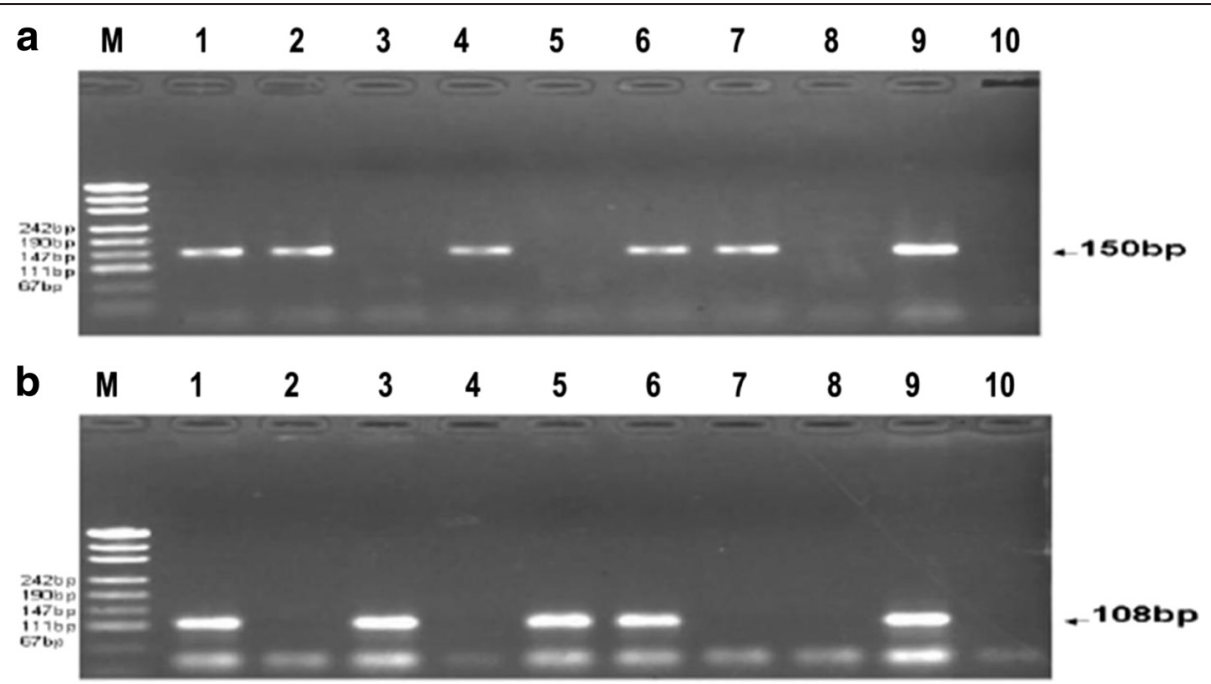

Fig. 1 Electrophoretic analysis of the HPV genotyping using PCR. (a) GP5 $5^{+} / G P 6^{+}$PCR. Lane 1, 2, 4, 6 and 7 in HPV infection (150 bp); Lane 3 and 4 without HPV infection; Lane 8, negative control; Lane 9, positive control; Lane 10, blank control; M, molecular weight marker. (b) Human papillomavirus PCR results. Lane 1, 3, 5 and 6 in HPV16 infection (150 bp); Lane 2, 4 and 7 without HPV16 infection; Lane 8, negative control; Lane 9, positive control; Lane 10, blank control; M, molecular weight marker 



b

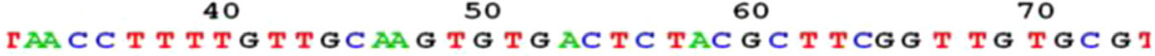

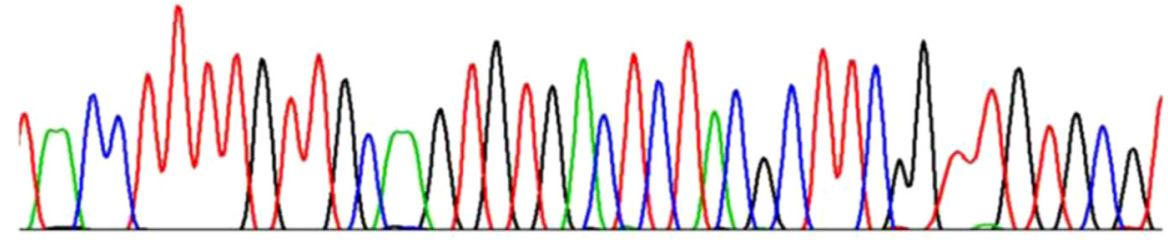

Fig. 2 Sequencing map of the genotype for the HPV L1 (a) and HPV 16E7 (b)

\section{Statistical analysis}

All statistical analyses were performed using SPSS version 17.0, U.S. Hardy-Weinberg equilibrium in controls was tested by chi-square tests comparing observed and expected genotype frequencies. The presence of HPV DNA in case-control study, Clinic pathological characteristics of HPV-positive and HPV-negative patients with ESCC, and the differences in the distributions of genotype of TAP1 I333V and D637G were analyzed by chi-square test. Logistic regression models for genotype were used to examine TAP1 I333V and D637G polymorphisms with risk of Kazakh EC, the effects of TAP1 D637G on risk of ESCC with different tumor depth, histological grade and clinical stage, and the association of HPV infection with TAP1 I333V and D637G polymorphisms in Kazakh EC. Results were given as $\mathrm{P}$ values, odds ratios (ORs) and $95 \%$ confidence intervals (95\% CIs). All statistical analyses were two-sided, and $P<0.05$ was considered statistically significant.

\section{Results}

Prevalence of HPV Infection in Kazakh EC Patients

Polymerase chain reaction (PCR) was employed to screen HPV infection statuses in 361 patients with EC and 66 controls, and the results are shown in Table 1. The prevalence of HPV DNA was higher in EC cases

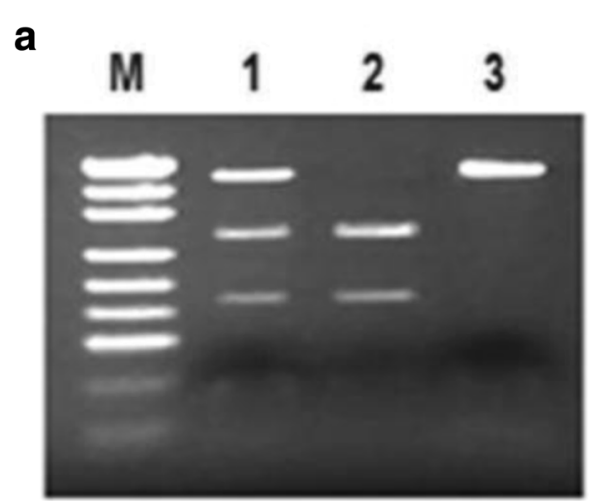

\section{b}

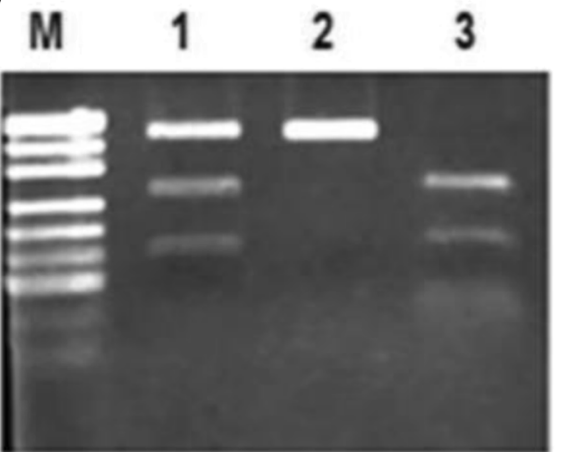

Fig. 3 PCR-RFLP assay for analyzing the TAP1 Codon333 and 637 polymorphisms. PCR product was digested by restriction enzyme and visualized in $3 \%$ agarose gel stained with ethidium bromide. (a) The typical genotypes of TAP1 Codon333 A/G. Lane 1: AG genotype (430,274 and 156 bp); lane 2: AA genotype (274 and 156 bp); lane 3: GG genotype (430 bp). (b) The typical genotypes of TAP1 Codon637 A/G. Lane 1: AG genotype (405,260 and 145 bp); lane 2: GG genotype (405 bp); lane 3: AA genotype (260 and 145 bp). M, molecular weight marker 




b

Codon637 GG

TOCTCTOCAOAOOTAOSCOAOOCTOOOAOCCAOC=

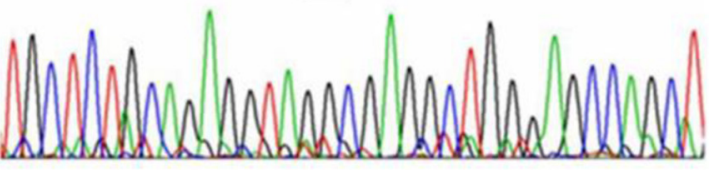

Codon637 AA



Codon637 AG

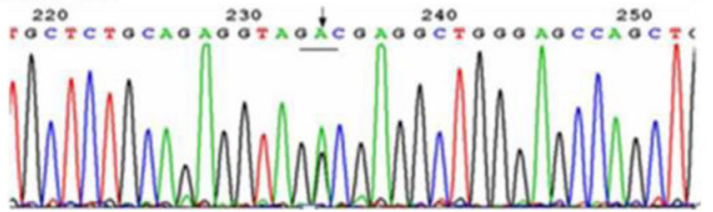

Fig. 4 Sequencing map of the genotype for the TAP1 Codon333 polymorphism (a) and TAP1 Codon637 polymorphism (b)

than that in the control group $(64.6 \%$ vs. $18.2 \%$, $P<0.001)$. Four HPV genotypes were identified in both EC tissue and normal esophageal tissue, including HPV16, 18, 31 and 45. HPV DNA was identified in 204 of 316 tumor tissue samples. There are totally $56 \mathrm{EC}$ patients and 3 normal controls with HPV multi-infection. Using the unconditional logistic regression models, the association between HPV infection and Kazakh patients with EC was evaluated. Apart from HPV45, the HPV detected, including HPV16 (OR, 3.941;95 \% CI, 1.926-7.955), HPV18 (OR, 3.390;95 \% CI, 1.411-8.145) and HPV31 (OR, 3.487; $95 \% \mathrm{CI}, 1.050-11.582$ ), exhibited a strong positive association with the risk of EC in Kazakhs. A higher OR value (OR, 8.196; 95 \% CI, 4.280-15.964) was observed in patients who are tested positive for HPV DNA (Table 1).

Since the high-risk HPVs, especially types 16 and 18, have been identified as the risk factor for cervical cancer as well as other cancers, to study further, HPV16 or/and 18 infected individuals were referred as the infected subjects and then, the association between risk of EC with HPV16 and 18 infection was assessed. The infection of HPV16, 18 and multi-infection of the two types significantly increase the risk for developing EC (OR 4.616, 95 \% CI 2.099-10.151; OR 4.522,95 \% CI. 1.553-13.165 and OR 6.029, 95 \% CI 1.395-26.057, respectively) in this area (Table 2).

\section{Association between HPV Infection and Clinical pathologic Characteristics of Patients with EC}

To identify whether the HPV infection influences the clinical pathologic characteristics in Kazakh patients with EC, the association of HPV infection with nine characteristics including age, gender, smoking, drinking, tumor location, histological grade, depth of invasion, lymph node metastasis and clinic stage was examined. Our results show that no significant difference in the nine investigated clinical pathologic characteristics is indicated between the EC patients with HPV and patients without (Table 3).

\section{TAP1 gene polymorphisms are predictors of EC risk in Kazakh populations}

To evaluate the role of TAP1 gene polymorphisms in the MHC class II region in the association of Kazakh EC, two potentially functional SNPs in TAP1 were tested. The distribution of genotypes and alleles is significantly different between cases and controls at TAP1 D637G $(P=0.040$ and $P=0.018$ respectively), but not at TAP1 I333V $(P=0.250$ and $P=0.118$ respectively). TAP1 D637G allele $(G)$ is significantly more common in patients than that in controls $(P=$ 0.018), suggesting that the $G$ allele is associated with EC in Kazakh population. Logistic regression models for genotype were derived to examine the association between TAP1 polymorphisms and the risk of Kazakh EC. Only TAP1 D637G polymorphism was found to be associated with cancer risk, which was significantly increased for carriers of at least one $G$ allele (OR, $1.659 ; 95 \% \mathrm{CI}, 1.112-2.474)$ and heterozygote carriers of the variant allele $\mathrm{G}(\mathrm{OR}, 1.626$; $95 \% \mathrm{CI}$, 1.080-2.449) (Table 4). 
Table 1 Analysis of the association between HPV infection and Kazakh patients with esophageal carcinoma

\begin{tabular}{llllr}
\hline Types & Case $(n=361)$ & Control $(n=66)$ & $x^{2}$ & OR (95 \% Cl) \\
\hline HPV L1 & $\mathrm{n}(\%)^{\mathrm{a}}$ & & \\
HPV16E7 & $204(64.6)$ & $12(18.2)$ & $47.786^{* * *}$ & $8.196(4.28-15.964)$ \\
HPV18E7 & $130(41.1)$ & $10(15.2)$ & $15.881^{* * *}$ & $3.941(1.926-7.955)$ \\
HPV31E7 & $80(25.3)$ & $6(9.1)$ & $8.240^{* *}$ & $3.390(1.411-8.145)$ \\
HPV45E7 & $45(14.2)$ & $3(4.5)$ & $4.671^{*}$ & $3.487(1.050-11.582)$ \\
Multiple infection & $23(7.3)$ & $1(1.5)$ & 3.080 & $5.102(0.677-38.466)$ \\
\hline
\end{tabular}

"**"represents $P<0.05$, "**"indicates $P<0.01$, "***"depicts $P<0.001$

${ }^{a}$ Because of the multiple infection, the total HPV-positive rate was smaller than the sum of the positive rates of each subtype

\section{Correlations of clinical pathological parameters and TAP1 D637G polymorphism in Kazakh patients with ESCC}

To investigate the contribution of confounding factors such as gender and age to the risk for Kazakh ESCC, stratification analyses were conducted to evaluate the potential association of genetic variants of the TAP1 D637G polymorphism with risk of subgroup populations (Table 5). Interestingly, the results showed that the risk effects of AG/GG genotypes were more evident in female subjects $(\mathrm{OR}=2.093)$. No significant association was found between TAP1 D637G polymorphism and ESCC with respect to age $(P>0.05)$.

The association between PLCE1 variants and histologic grade and clinical stage of ESCC was further evaluated (Table 5). When the ESCC patients were divided into 2 subgroups, T1/T2 and T3/T4, according to the AJCC TNM classification of carcinoma of esophagus, the carriers of AG/GG genotypes had a significantly increased risk for T1/T2 ESCC $(P=0.004, \mathrm{OR}=2.040)$. When the ESCC patients were divided into 2 subgroups, stage I/II and stage III/IV, the combined risk genotypes were found to be associated with stage I/II ESCC ( $P=$ $0.016, \mathrm{OR}=1.721$ ).

\section{Relation of HPV positive of Kazakh patients with EC to TAP1 genotype}

The results of genotype frequencies of the two investigated TAP1 gene polymorphisms in HPV-positive and HPV-negative patients are summarized in Table 6. The distribution of genotypes was significantly different between patients with HPV infection and those without at
TAP1 D637G $(P<0.001)$, but not at TAP1 I333V $(P=$ 0.056). To study further, we analyze the association between TAP1 D637G polymorphisms and HPVassociated Kazakh patients with EC. Differing from the wild-type AA homozygote, the combined AG/GG or AG variant genotypes were significantly associated with HPV-positive in EC patients (OR 0.255, 95 \% CI 0.1270.511; and OR 0.281, $95 \%$ CI 0.144-0.551, respectively), although the homozygous mutant type of TAP D637G (GG) exhibited no association with HPV-positive EC patients $(P=0.691)$. We further evaluated the association between the risk of genotypes of TAP1 and risk of HPVassociated ESCC stratified by tumor depth. Interestingly, the results showed that differences between the protective effects of heterozygote and combined genotypes of TAP1 D637 were more significantly in T1/T2 subjects $(P=0.004, \mathrm{OR}=0.028$ and $P=0.006, \quad \mathrm{OR}=0.283$, respectively) than in $\mathrm{T} 3 / \mathrm{T} 4$ subjects $(P=0.020, \mathrm{OR}=0.286$ and $P=0.026, \mathrm{OR}=0.311$ respectively).

\section{Discussion}

More than one hundred HPV subtypes have been described [45], over forty of which have been shown to be involved in human disease, and these subtypes are traditionally characterized by the sequence of their L1 gene. The involvement of HPV in etiology of EC has drawn interest in the past three decades since Syrjanen first found $40 \%$ of EC patients had similar histological changes to the genital warts in reproductive tract in 1982 [14]. The majority of studies have identified HPV in ESCC samples, with infection rates ranging from 17.1

Table 2 Association of HPV 16 or/and 18 infection with risk of EC

\begin{tabular}{|c|c|c|c|c|c|}
\hline \multicolumn{2}{|l|}{ Types } & \multirow{2}{*}{$\begin{array}{l}\text { Case }(n=361) \\
\mathrm{n}(\%)\end{array}$} & \multirow{2}{*}{$\begin{array}{l}\text { Control }(n=66) \\
\mathrm{n}(\%)\end{array}$} & \multirow[t]{2}{*}{$x^{2}$} & \multirow[t]{2}{*}{$\mathrm{OR}(95 \% \mathrm{Cl})$} \\
\hline HPV16E7 & HPV18E7 & & & & \\
\hline Negative & Negative & $138(43.7)$ & $52(78.8)$ & & 1.000 \\
\hline Positive & Negative & $98(31.0)$ & $8(12.1)$ & $16.541^{* * *}$ & $4.616(2.099-10.151)$ \\
\hline Negative & Positive & $48(15.2)$ & $4(6.0)$ & $10.063^{* *}$ & $4.522(1.553-13.166)$ \\
\hline Positive & Positive & $32(10.1)$ & $2(3.0)$ & $7.277^{* *}$ & $6.029(1.395-26.057)$ \\
\hline
\end{tabular}

"*"represents $P<0.05$, "**"indicates $P<0.01$, "****depicts $P<0.001$ 
Table 3 Clinic pathological characteristics of HPV-positive and HPV-negative patients with ESCC

\begin{tabular}{|c|c|c|c|c|c|}
\hline \multirow[t]{2}{*}{ Characteristics } & \multirow[t]{2}{*}{ Number } & \multirow{2}{*}{$\begin{array}{l}\mathrm{HPV}^{+} \text {Patients } n=204 \\
\mathrm{n}(\%)\end{array}$} & \multirow{2}{*}{$\begin{array}{l}\text { HPV }^{-} \text {Patients } n=112 \\
\mathrm{n}(\%)\end{array}$} & \multirow[t]{2}{*}{$x^{2}$} & \multirow[t]{2}{*}{$P$ value } \\
\hline & & & & & \\
\hline Age (years), mean $\pm S D$ & 316 & $53.01 \pm 8.202$ & $52.67 \pm 10.141$ & & $0.746^{a}$ \\
\hline Age (years) & & & & 0.301 & 0,584 \\
\hline$<55$ & 173 & $114(65.9)$ & $59(34.1)$ & & \\
\hline$\geq 55$ & 113 & $90(62.9)$ & $53(37.1)$ & & \\
\hline Gender & & & & 2.692 & 0,101 \\
\hline Male & 187 & $127(67.9)$ & $60(32.1)$ & & \\
\hline Female & 129 & $76(58.9)$ & $53(41.1)$ & & \\
\hline Smoking & & & & 0.081 & 0.775 \\
\hline Yes & 82 & $54(65.9)$ & $28(34.1)$ & & \\
\hline No & 234 & $150(64.1)$ & $84(35.9)$ & & \\
\hline Drinking & & & & 2.149 & 0.143 \\
\hline Yes & 65 & $47(72.3)$ & $18(27.7)$ & & \\
\hline No & 251 & $157(62.5)$ & $94(37.5)$ & & \\
\hline Location of the tumor & & & & 1.311 & 0.519 \\
\hline The upper thoracic portion & 19 & $10(52.6)$ & $9(47.4)$ & & \\
\hline The mid-thoracic portion & 170 & $112(65.9)$ & $58(34.1)$ & & \\
\hline The lower thoracic portion & 127 & $82(64.6)$ & $45(35.4)$ & & \\
\hline Histologic grade & & & & 0.331 & 0.848 \\
\hline Well-differentiated $\left(G_{1}\right)$ & 106 & $67(63.2)$ & $39(36.8)$ & & \\
\hline Moderately differentiated $\left(G_{2}\right)$ & 162 & $107(66.0)$ & $55(34.0)$ & & \\
\hline Poorly differentiated $\left(\mathrm{G}_{3}\right)$ & 48 & $30(62.5)$ & $18(37.5)$ & & \\
\hline Depth of invasion & & & & 0320 & 0.572 \\
\hline $\mathrm{T} 1 / \mathrm{T} 2$ & 188 & 119 (63.3) & $69(36.7)$ & & \\
\hline $\mathrm{T} 3 / \mathrm{T} 4$ & 128 & $85(66.4)$ & $43(33.6)$ & & \\
\hline Lymph node metastasis & & & & 1.127 & 0.288 \\
\hline No & 193 & $129(66.8)$ & $64(33.2)$ & & \\
\hline Yes & 123 & $75(61.0)$ & $48(39.0)$ & & \\
\hline Clinical stage & & & & 1.847 & 0.174 \\
\hline stage $|/| \mid$ & 231 & $144(62.3)$ & $87(37.7)$ & & \\
\hline stage III/IV & 85 & $60(70.6)$ & $25(29.4)$ & & \\
\hline
\end{tabular}

${ }^{\text {a }}$ Student's test

[46] to $78.11 \%$ [44], detected via amplification of the L1 gene. One study reported an infection rate of $100 \%$, which was determined by detection of the HPV16 E6 and E7 genes in early cancer cases in a high-risk area using PCR and ISH in Anyang, Henan [47]. While a recent study in east China, in which 23 different HPV types was screened using a human papillomavirus genotyping kit and the $\mathrm{P} 16^{\mathrm{INK} 4 \mathrm{a}}$ protein was detected using immunohistochemistry (ISH), shows the absence of human papillomavirus in EC [20]. These two extreme values may best illustrated that the incidence of $\mathrm{HPV}$ infection in EC varies from the high-incidence to the low-incidence areas $[15,17,22,47-51]$, which is not in accordance with HPV infection in cervical carcinoma.
This finding suggests that HPV infection exerts a complex effect on carcinogenesis of the EC.

The PCR method was adopted to assess prevalence of four high-risk HPV in the 361 Kazakh patients with EC and 66 cancer-free controls obtained from several hospitals between 1990 and 2014 in the Kazakh Autonomous Prefecture of Xinjiang, an area with high incidence of EC located in northwestern China. The significantly high prevalence of HPV in the Kazakh patients with EC indicated that HPV infection significantly affect the carcinogenesis of the EC in Kazakh population (64.6\% vs. $18.2 \%, P<0.001)$. It has been shown that human papilloma virus is found frequently in ESCCs in high incidence areas. What's more, the frequency of HPV 
Table 4 Association of TAP1 gene polymorphisms with risk of Kazakh ESCC

\begin{tabular}{|c|c|c|c|c|}
\hline Genotype or allele & Case n (\%) & Control n (\%) & $P$ value & OR $(95 \% \mathrm{Cl})$ \\
\hline \multicolumn{5}{|l|}{ TAP1 D637G } \\
\hline$A A^{a}$ & $73(48.7)$ & $173(61.1)$ & & 1.000 (reference) \\
\hline$A G$ & $70(46.7)$ & $102(36.1)$ & 0.019 & $1.626(1.080-2.449)$ \\
\hline GG & $7(4.7)$ & $8(2.8)$ & $0.246^{\mathrm{b}}$ & $2.074(0.725-5.930)$ \\
\hline \multicolumn{5}{|c|}{ Combined variant genotypes } \\
\hline $\mathrm{AG}+\mathrm{GG}$ & 77 (51.3) & $110(38.9)$ & 0.013 & $1.659(1.112-2.474)$ \\
\hline$A^{a}$ & $216(72.0)$ & $448(79.2)$ & & 1.000 (reference) \\
\hline G & $84(28.0)$ & $118(20.8)$ & 0.018 & $1.477(1.068-2.040)$ \\
\hline \multicolumn{5}{|l|}{ TAP1 I333V } \\
\hline$A A^{a}$ & $82(54.7)$ & $134(47.3)$ & & 1.000 (reference) \\
\hline$A G$ & $62(41.3)$ & $130(46.0)$ & 0.232 & $0.780(0.518-1.173)$ \\
\hline GG & $6(4.0)$ & $19(6.7)$ & 0.170 & $0.516(0.198-1.345)$ \\
\hline \multicolumn{5}{|c|}{ Combined variant genotypes } \\
\hline $\mathrm{AG}+\mathrm{GG}$ & $68(45.3)$ & $149(52.7)$ & 0.112 & $0.724(0.486-1.079)$ \\
\hline$A^{a}$ & $226(72.0)$ & $398(70.3)$ & & 1.000 (reference) \\
\hline G & $74(24.7)$ & $168(29.7)$ & 0.118 & $0.776(0.564-1.067)$ \\
\hline
\end{tabular}

aReference group

${ }^{\mathrm{b}}$ Fisher's exact test

Table 5 Correlations of clinicopathological parameters and TAP1 D637G polymorphism in Kazakh patients with ESCC

\begin{tabular}{|c|c|c|c|}
\hline \multicolumn{4}{|l|}{ Gender $^{a}$} \\
\hline Male & $48 / 92$ & $46 / 62$ & $1.422(0.848-2.385)$ \\
\hline Female & $25 / 81$ & $31 / 48$ & $2.093(1.107-3.954)^{*}$ \\
\hline \multicolumn{4}{|l|}{$\mathrm{Age}^{\mathrm{a}}$} \\
\hline$\leq 52$ & $30 / 91$ & $30 / 60$ & $1.517(0.831-2.769)$ \\
\hline$>52$ & $43 / 82$ & $37 / 50$ & $1.411(0804-2.478)$ \\
\hline \multicolumn{4}{|c|}{ Tumor depth $^{\mathrm{b}}$} \\
\hline $\mathrm{T} 1 / \mathrm{T} 2$ & $37 / 173$ & $48 / 110$ & $2.040(1.249-3.333)^{* *}$ \\
\hline $\mathrm{T} 3 / \mathrm{T} 4$ & $36 / 173$ & $29 / 110$ & $1.267(0.735-2.184)$ \\
\hline \multicolumn{4}{|c|}{ Histologic grade $(G)^{b}$} \\
\hline G1 & $27 / 173$ & $27 / 110$ & $1.573(0.877-2.822)$ \\
\hline G2 & $38 / 173$ & $40 / 110$ & $1.656(0.999-2.741)$ \\
\hline G3 & $8 / 173$ & $10 / 110$ & $1.966(0.753-5134)$ \\
\hline \multicolumn{4}{|c|}{ Clinical stage $\mathrm{b}^{\mathrm{b}}$} \\
\hline$|/| \mid$ & $53 / 173$ & $58 / 110$ & $1.721(1.106-2.679)^{*}$ \\
\hline III/IV & $20 / 173$ & $19 / 110$ & $1.494(0.763-2.925)$ \\
\hline
\end{tabular}

We consider the common homozygotes of TAP1 as ORs of 1.000 for the reference genotype

"**"represents $P<0.05$, "***indicates $P<0.01$, "****"depicts $P<0.001$

${ }^{a}$ Stratification analysis to evaluate the effects of variant genotypes on the risk of ESCC by age and sex

${ }^{b}$ Logistic regression analysis for the effects of TAP1 variants on risk of ESCC with different tumor depth, histologic grade and clinical stage through logistic regression analyses. G1: well differentiated; G2: moderately differentiated; G3: poorly differentiated 
Table 6 Stratification analysis to evaluate the association of HPV positive patients with TAP1 polymorphisms in Kazakh ESCC by tumor depth

\begin{tabular}{|c|c|c|c|c|c|c|}
\hline \multirow[t]{2}{*}{ Parameters } & \multicolumn{2}{|c|}{ TAP1 D637G (HPV ${ }^{+} / \mathrm{HPV}^{-}$patients) } & \multirow[t]{2}{*}{ OR $(95 \% \mathrm{Cl})$} & \multicolumn{2}{|c|}{ TAP1 I333V (HPV+/HPV patients) } & \multirow[t]{2}{*}{ OR $(95 \% \mathrm{Cl})$} \\
\hline & $\overline{\mathrm{AA}^{a}}$ & AG/GG & & $\overline{A A^{a}}$ & $\mathrm{AG} / \mathrm{GG}$ & \\
\hline \multicolumn{7}{|c|}{ Tumor depth } \\
\hline $\mathrm{T} 1 / \mathrm{T} 2$ & $21 / 16$ & $13 / 35$ & $0.283(0.114-0.703)^{* *}$ & $23 / 27$ & $11 / 24$ & $0.538(0.218-1.330)$ \\
\hline $\mathrm{T} 3 / \mathrm{T} 4$ & $27 / 9$ & $14 / 15$ & $0.311(0.109-0.888)^{*}$ & $21 / 11$ & 20/13 & $0.806(0.294-2.212)$ \\
\hline $\mathrm{T} 1-\mathrm{T} 4$ & $48 / 25$ & $48 / 25$ & $0.281(0.144-0.551)^{* * *}$ & $44 / 38$ & $31 / 37$ & $0.724(0.380-1.380)$ \\
\hline
\end{tabular}

"*"represents $P<0.05$, “**"indicates $P<0.01$, "***"depicts $P<0.001$

${ }^{a}$ Reference group. We consider the common homozygotes of TAP1 as ORs of 1.00 for the reference genotype

infection in the tumors observed in the current study much higher than the average rate from a systematic review and a formal meta-analysis of the literature on HPV detection in 10,234 EC cases from 1954 to 2012 [52]. Additionally, our present study showed the incidence of HPV16 infection in Kazakh EC patients $(41.1 \%)$ was significantly higher than in the control group (15.2\%), and, it has been proposed that HPV16 infection may play a role in esophageal carcinogenesis. A similar observation was also revealed in previous studies in Xinjiang Kazakhs $[23,53]$. Nevertheless, some studies demonstrate no relationship between HPV infection and EC, which may reflect discrepancy of different race, different ethnic and different region. In our study, strict quality controls on the object and method of the study was performed strictly. Therefore, we can confirm that HPV infection is one of the important factors in high incidence of Xinjiang ethnic Kazakh EC.

The data confirmed no significant association between the presence of HPV and the histological grade of EC. While in certain reports, well-differentiated tumors tended to have either HPV16 or HPV16/6 infection, suggesting that HPV can initiate the development of EC and explaining the higher survival rate indicated in HPVpositive patients with EC [13, 19]. Nevertheless, other study reported that a positive HPV16/18 rate and viral load were more often in poorly differentiated EC cases, although no significant correlation was confirmed [24]. The discrepant results in the literatures may be attributed to the difference in detection methods, sample size, and patient heterogeneity because of the variety of ethnicities in the sample although the samples cases were obtained from the same region. Thus, the conclusions concerning the influence of HPV on various differentiation of EC warrant confirmation.

Host factors such as the immune systems and genetic factors also seem to be important factors in HPV persistence and subsequent cancer carcinogenesis [52, 54]. The polymorphisms of TAP1 genes may result in the conformational and functional change of TAP, which can influence the antigen peptide selection and transport process [55]. There are several studies on the relationship between TAP (including TAP1 and TAP2) polymorphisms and various carcinoma, and only TAP1 polymorphisms have been confirmed to be susceptible to various tumor types. One study shows that no significant difference in genotype distribution of TAP1 and TAP2 polymorphisms was observed in women with cervical intraepithelial neoplasm (CIN) and controls [56], and a similar study conducted in India succeeded to reproduce this observation [57], however, in another similar study, significant differences in allele distribution between women with high-grade cervical neoplasm (CIN II or III) and women without was seen for both TAP1 I333V $(P=0.02)$ and TAP1 D637G $(P=0.01)$ [58]. In addition, $G$ allele at TAP1 Codon 637 is associated with nasopharyngeal carcinoma (NPC) in Han population in Yunnan, China (OR, 1.88; $95 \% \mathrm{CI}, 1.35-2.82$; $P<0.001$ ), and EBV pathogenesis in NPC might be facilitated by polymorphisms in the TAP1 proteins [59].

The present case-control study has analyzed the association between TAP gene polymorphisms and the risk of EC in Kazakh population in Xinjiang, China. The important finding is that the heterozygote of TAP1 D637G (AG) genotypes were associated with a 1.626-fold higher risk for the development of EC, whereas the GG genotype was not associated with the risk of developing EC, suggesting that G allele at TAP1 D637G is a risk factor for EC, which is contrary to the study of Cao et al [44]. The reason for this discrepancy might be due to genetic heterogeneity between Kazakh and Han population, according to the theory that the Han Chinese population, though seeming homogeneous, exhibits a complicated substructure as the genetics of different Han Chinese populations differ greatly [60]. In the current samples, false-positive or false-negative associations owing to population substructure were less likely to exist, because the carefully ascertained, relatively homogeneous casecontrol samples of northwestern Kazakh belong to a single geographic location of the province of Xinjiang. This polymorphism has been shown to vary with ethnic and geographical distribution. However, its influence has not been elucidated in the Kazakh population.

Epidemiologic and molecular studies have shown that all virus agents and the genetic factors are involved in 
the initiation and progression of EC [17]. Another important finding in the present study is that HPV-positive rate is lower for patients carrying allele $\mathrm{G}$ at TAP1 D637G, and this provides an illustration to the theory that TAP facilitates the detection of HPV by MHC-I molecules and contributes to detection and eradication of HPV despite various immune evasion mechanisms of the virus [61].

\section{Conclusion}

Taken together the present study demonstrated that G allele at TAP1 Codon637 decreases susceptibility to HPV infection in patients with EC among the Kazakh populations, however, it is associated with an increased risk of EC in this ethnic. This finding suggests that the polymorphism of TAP1 Codon637 exerts complicated influence on EC in Kazakh population. However, given that the mechanisms by which TAP1 polymorphisms may influence the course of HPV infections remains under investigation, further studies need to be conducted to elucidate the influence of TAP1 polymorphisms in HPV-associated EC in the Kazakh population.

\section{Competing interests}

The authors declare that they have no competing interests.

\section{Authors' contributions}

$N Z$, LY, and LC recruited patients, collected the data, performed the experiment and drafted the manuscript. TL, TJ, HP, SZ, DW, RL, CL, JJ, WL, LW, JH, SL, CW participated in patients' recruitment, study materials collection and experiment design. FL, YC and XC participated in the design of the study, interpretation of data and revision of the manuscript. All authors read and approved the final manuscript.

\section{Acknowledgements}

This work was supported by grants from the Ministry of Science and Technology of China (2012AA02A503) and the National Natural Science Foundation of China (No. 81160301, 81360358, 81460362, 81260301, 81460416), the Major science and technology projects of Shihezi University (No. gxjs2014-zdgg06), the jointly oundation for nurturing the outstanding young scientists of Shihezi University (No.2013ZRKXYQ -YD19). The funders had no role in study design, data collection and analysis, decision to publish, or preparation of the manuscript.

\section{Author details}

${ }^{1}$ Department of Pathology and Key Laboratory for Xinjiang Endemic and Ethnic Diseases, Shihezi University School of Medicine, North 4th Road, Shihezi, Xinjiang 832002, China. ${ }^{2}$ Department of Oncology, Tongji Hospital, Huazhong University of Science and Technology, Wuhan 430030, China. ${ }^{3}$ Department of Pathology, University of Pittsburgh, Pittsburgh, PA 15261, USA.

Received: 30 April 2015 Accepted: 3 July 2015

Published online: 25 July 2015

\section{References}

1. Parkin DM, Bray F, Ferlay J, Pisani P. Global cancer statistics, 2002. CA Cancer J Clin. 2005;55:74-108.

2. Lambert $R$, Hainaut $P$. The multidisciplinary management of gastrointestinal cancer. Epidemiology of oesophagogastric cancer. Best Pract Res Clin Gastroenterol. 2007;21:921-45.

3. Kamangar F, Dores GM, Anderson WF. Patterns of cancer incidence, mortality, and prevalence across five continents: defining priorities to reduce cancer disparities in different geographic regions of the world. J Clin Oncol. 2006;24:2137-50.
4. Zheng S, Vuitton L, Sheyhidin I, Vuitton DA, Zhang Y, Lu X. Northwestern China: a place to learn more on oesophageal cancer. Part one: behavioural and environmental risk factors. Eur J Gastroenterol Hepatol. 2010;22:917-25.

5. Morita M, Kumashiro R, Kubo N, Nakashima Y, Yoshida R, Yoshinaga K, et al. Alcohol drinking, cigarette smoking, and the development of squamous cell carcinoma of the esophagus: epidemiology, clinical findings, and prevention. Int J Clin Oncol. 2010;15:126-34.

6. Brown LM, Hoover R, Silverman D, Baris D, Hayes R, Swanson GM, et al. Excess incidence of squamous cell esophageal cancer among US Black men: role of social class and other risk factors. Am J Epidemiol. 2001;153:114-22

7. Messmann H. Squamous cell cancer of the oesophagus. Best Pract Res Clin Gastroenterol. 2001;15:249-65.

8. Tran GD, Sun XD, Abnet CC, Fan JH, Dawsey SM, Dong ZW, et al. Prospective study of risk factors for esophageal and gastric cancers in the Linxian general population trial cohort in China. Int J Cancer. 2005;113:456-63.

9. Kamangar F, Chow WH, Abnet CC, Dawsey SM. Environmental causes of esophageal cancer. Gastroenterol Clin North Am. 2009;38:27-57.

10. Abate E, Aseffa A, El-Tayeb M, El-Hassan I, Yamuah L, Mihret W, et al. Genotyping of human papillomavirus in paraffin embedded cervical tissue samples from women in Ethiopia and the Sudan. J Med Virol. 2013;85:282-7.

11. Gillison ML, Koch WM, Capone RB, Spafford M, Westra WH, Wu L, et al. Evidence for a causal association between human papillomavirus and a subset of head and neck cancers. J Natl Cancer Inst. 2000;92:709-20.

12. Hansson BG, Rosenquist $K$, Antonsson A, Wennerberg J, Schildt EB, Bladstrom A, et al. Strong association between infection with human papillomavirus and oral and oropharyngeal squamous cell carcinoma: a population-based case-control study in southern Sweden. Acta Otolaryngol. 2005;125:1337-44.

13. Castillo A, Aguayo F, Koriyama C, Torres M, Carrascal E, Corvalan A, et al. Human papillomavirus in esophageal squamous cell carcinoma in Colombia and Chile. World J Gastroenterol. 2006;12:6188-92.

14. Syrjanen K, Pyrhonen S, Aukee S, Koskela E. Squamous cell papilloma of the esophagus: a tumour probably caused by human papilloma virus (HPV). Diagn Histopathol. 1982:5:291-6.

15. Antonsson A, Nancarrow DJ, Brown IS, Green AC, Drew PA, Watson DI, et al. High-risk human papillomavirus in esophageal squamous cell carcinoma. Cancer Epidemiol Biomarkers Prev. 2010;19:2080-7.

16. Guo F, Liu Y, Wang X, He Z, Weiss NS, Madeleine MM, et al. Human papillomavirus infection and esophageal squamous cell carcinoma: a case-control study. Cancer Epidemiol Biomarkers Prev. 2012;21:780-5.

17. Hu H, Yang J, Sun Y, Yang Y, Qian J, Jin L, et al. Putatively functional PLCE1 variants and susceptibility to esophageal squamous cell carcinoma (ESCC): a case-control study in eastern Chinese populations. Ann Surg Oncol. 2012;19:2403-10.

18. Liu H, Li J, Diao M, Cai Z, Yang J, Zeng Y. Statistical analysis of human papillomavirus in a subset of upper aerodigestive tract tumors. J Med Virol. 2013;85:1775-85

19. Cui $X$, Chen Y, Liu L, Li L, Hu J, Yang L, et al. Heterozygote of PLCE1 rs2274223 increases susceptibility to human papillomavirus infection in patients with esophageal carcinoma among the Kazakh populations. J Med Virol. 2014:86:608-17.

20. Teng H, Li X, Liu X, Wu J, Zhang J. The absence of human papillomavirus in esophageal squamous cell carcinoma in East China. Int J Clin Exp Pathol. 2014;7:4184-93.

21. Hubbard RA. Human papillomavirus testing methods. Arch Pathol Lab Med. 2003;127:940-5.

22. Kamangar F, Qiao YL, Schiller JT, Dawsey SM, Fears T, Sun XD, et al. Human papillomavirus serology and the risk of esophageal and gastric cancers: results from a cohort in a high-risk region in China. Int J Cancer. 2006;119:579-84

23. Hu J, Li L, Pang L, Chen Y, Yang L, Liu C, et al. HLA-DRB1*1501 and HLADQB1*0301 alleles are positively associated with HPV16 infection-related Kazakh esophageal squamous cell carcinoma in Xinjiang China. Cancer Immunol Immunother. 2012;61:2135-41.

24. Liu T, Liu Q, Liang M, Zheng S, Li XL, Lu X, et al. Viral load of HPV 16/18 in esophageal squamous cell carcinoma in three ethnic groups living in Xinjiang Autonomous Region, China. Mol Biol Rep. 2013;40:2045-52.

25. Hanahan D, Weinberg RA. Hallmarks of cancer: the next generation. Cell. 2011;144:646-74.

26. Heemels MT, Ploegh H. Generation, translocation, and presentation of MHC class I-restricted peptides. Annu Rev Biochem. 1995;64:463-91. 
27. Germain RN. MHC-dependent antigen processing and peptide presentation: providing ligands for T lymphocyte activation. Cell. 1994;76:287-99.

28. Thor Straten P, Kirkin AF, Seremet T, Zeuthen J. Expression of transporter associated with antigen processing 1 and 2 (TAP1/2) in malignant melanoma cell lines. Int J Cancer. 1997;70:582-6.

29. Spies T, Bresnahan M, Bahram S, Arnold D, Blanck G, Mellins E, et al. A gene in the human major histocompatibility complex class $\|$ region controlling the class I antigen presentation pathway. 1990. J Immunol. 2008;180:2737-40.

30. Abele R, Tampe R. Function of the transport complex TAP in cellular immune recognition. Biochim Biophys Acta. 1999;1461:405-19.

31. Parcej $D$, Tampe R. ABC proteins in antigen translocation and viral inhibition. Nat Chem Biol. 2010;6:572-80

32. Cresswell P, Bangia N, Dick T, Diedrich G. The nature of the MHC class I peptide loading complex. Immunol Rev. 1999;172:21-8.

33. Liu Q, Hao C, Su P, Shi J. Down-regulation of HLA class I antigen-processing machinery components in esophageal squamous cell carcinomas: association with disease progression. Scand J Gastroenterol. 2009;44:960-9.

34. Lee HJ, Ha SJ, Han H, Kim JW. Distribution of HLA-A, B alleles and polymorphisms of TAP and LMP genes in Korean patients with atopic dermatitis. Clin Exp Allergy. 2001;31:1867-74.

35. Yu MC, Huang CM, Wu MC, Wu JY, Tsai FJ. Association of TAP2 gene polymorphisms in Chinese patients with rheumatoid arthritis. Clin Rheumatol. 2004;23:35-9.

36. Correa PA, Molina JF, Pinto LF, Arcos-Burgos M, Herrera M, Anaya JM. TAP1 and TAP2 polymorphisms analysis in northwestern Colombian patients with systemic lupus erythematosus. Ann Rheum Dis. 2003;62:363-5.

37. Khu YL, Tan YJ, Lim SG, Hong W, Goh PY. Hepatitis C virus non-structural protein NS3 interacts with LMP7, a component of the immunoproteasome, and affects its proteasome activity. Biochem J. 2004;384:401-9.

38. Lautscham G, Rickinson A, Blake N. TAP-independent antigen presentation on MHC class I molecules: lessons from Epstein-Barr virus. Microbes Infect. 2003:5:291-9.

39. Neumeister C, Nanan R, Cornu T, Luder C, ter Meulen V, Naim H, et al. Measles virus and canine distemper virus target proteins into a TAPindependent MHC class I-restricted antigen-processing pathway. J Gen Virol. 2001;82:441-7.

40. Soundravally R, Hoti SL. Significance of transporter associated with antigen processing 2 (TAP2) gene polymorphisms in susceptibility to dengue viral infection. J Clin Immunol. 2008;28:256-62.

41. Yang T, McNally BA, Ferrone S, Liu Y, Zheng P. A single-nucleotide deletion leads to rapid degradation of TAP-1 mRNA in a melanoma cell line. J Biol Chem. 2003:278:15291-6.

42. Kloor M, Becker C, Benner A, Woerner SM, Gebert J, Ferrone S, et al. Immunoselective pressure and human leukocyte antigen class I antigen machinery defects in microsatellite unstable colorectal cancers. Cancer Res. 2005;65:6418-24.

43. Vermeulen CF, Jordanova ES, ter Haar NT, Kolkman-Uljee SM, de Miranda $N F$, Ferrone $S$, et al. Expression and genetic analysis of transporter associated with antigen processing in cervical carcinoma. Gynecol Oncol. 2007;105:593-9.

44. Cao B, Tian X, Li Y, Jiang P, Ning T, Xing H, et al. LMP7/TAP2 gene polymorphisms and HPV infection in esophageal carcinoma patients from a high incidence area in China. Carcinogenesis. 2005;26:1280-4.

45. de Villiers EM, Fauquet C, Broker TR, Bernard HU, zur Hausen H. Classification of papillomaviruses. Virology. 2004;324:17-27.

46. de Villiers EM, Lavergne D, Chang F, Syrjanen K, Tosi P, Cintorino M, et al. An interlaboratory study to determine the presence of human papillomavirus DNA in esophageal carcinoma from China. Int J Cancer. 1999:81:225-8

47. Li T, Lu ZM, Chen KN, Guo M, Xing HP, Mei Q, et al. Human papillomavirus type 16 is an important infectious factor in the high incidence of esophageal cancer in Anyang area of China. Carcinogenesis. 2001;22:929-34.

48. Chang F, Syrjanen S, Shen Q, Cintorino M, Santopietro R, Tosi P, et al. Evaluation of HPV, CMV, HSV and EBV in esophageal squamous cell carcinomas from a high-incidence area of China. Anticancer Res. 2000;20:3935-40.

49. Feng S, Zheng J, Du X, Tan Y, Yang H, Zhang H, et al. Human papillomavirus was not detected by PCR using multiple consensus primer sets in esophageal adenocarcinomas in Chinese patients. J Med Virol. 2013;85:1053-7.
50. Goto A, Li CP, Ota S, Niki T, Ohtsuki Y, Kitajima S, et al. Human papillomavirus infection in lung and esophageal cancers: analysis of 485 Asian cases. J Med Virol. 2011;83:1383-90.

51. Peixoto Guimaraes D, Hsin Lu S, Snijders P, Wilmotte R, Herrero R, Lenoir G, et al. Absence of association between HPV DNA, TP53 codon 72 polymorphism, and risk of oesophageal cancer in a high-risk area of China. Cancer Lett. 2001;162:231-5.

52. Syrjanen K. Geographic origin is a significant determinant of human papillomavirus prevalence in oesophageal squamous cell carcinoma: Systematic review and meta-analysis. Scand J Infect Dis. 2013;45:1-18.

53. Hu JM, Li L, Chen YZ, Pang LJ, Yang L, Liu CX, et al. Human papillomavirus type 16 infection may be involved in esophageal squamous cell carcinoma carcinogenesis in Chinese Kazakh patients. Dis Esophagus. 2013;26:703-7.

54. Connor ME, Stern PL. Loss of MHC class-I expression in cervical carcinomas. Int J Cancer. 1990;46:1029-34

55. Quadri SA, Singal DP. Peptide transport in human lymphoblastoid and tumor cells: effect of transporter associated with antigen presentation (TAP) polymorphism. Immunol Lett. 1998;61:25-31.

56. Natter C, Polterauer S, Rahhal-Schupp J, Cacsire Castillo-Tong D, Pils S, Speiser $P$, et al. Association of TAP gene polymorphisms and risk of cervical intraepithelial neoplasia. Dis Markers. 2013;35:79-84.

57. Kordi Tamandani DM, Sobti RC, Shekari M, Husseini SA, Suri V. No association of TAP1 and TAP2 genes polymorphism with risk of cervical cancer in north Indian population. J Assist Reprod Genet. 2009;26:173-8.

58. Einstein MH, Leanza S, Chiu LG, Schlecht NF, Goldberg GL, Steinberg BM et al. Genetic variants in TAP are associated with high-grade cervical neoplasia. Clin Cancer Res. 2009;15:1019-23.

59. Sui J, Mo Q, Li XJ, Ma J, Ren YX, Gao W, et al. [Transporter associated with antigen processing 1 637A/G gene polymorphisms and susceptibility to nasopharyngeal carcinoma in Han population in Yunnan Province, China]. Zhonghua Er Bi Yan Hou Tou Jing Wai Ke Za Zhi. 2010;45:238-43.

60. Jin L, Su B. Natives or immigrants: modern human origin in east Asia. Nat Rev Genet. 2000;1:126-33.

61. Engelhard VH. How cells process antigens. Sci Am. 1994;271:54-61

\section{Submit your next manuscript to BioMed Central and take full advantage of:}

- Convenient online submission

- Thorough peer review

- No space constraints or color figure charges

- Immediate publication on acceptance

- Inclusion in PubMed, CAS, Scopus and Google Scholar

- Research which is freely available for redistribution 